\title{
EXPERIMENTAL STUDY ON MECHANICAL PROPERTIES OF M30 CONCRETE WITH PARTIAL REPLACEMENT OF CEMENT AND FINE AGGREGATE WITH SILICA FUME AND COPPER SLAG
}

\author{
Pranshu Saxena ${ }^{1}$ \\ ${ }^{I}$ Department of Civil Engineering, IFTM University, Moradabad, U.P
}

\begin{abstract}
The present investigation revealed the effect of using silica fume and copper slag as a partial replacement of cement and fine aggregate, respectively on the mechanical properties of the concrete. Due to the depletion of natural sand resource worldwide with the increment of industrial waste, simultaneously, partial replacements of fine aggregate with copper slag have been attempted. Therefore, the primary objective of this research work was to conduct the study on M30 concrete whose compressive, tensile and flexural strength was observed. For this study, the fixed amount of silica fume (10\%) and the different proportion of copper slag $(10 \%, 20 \%, 30 \%, 40 \%$ and $50 \%)$ were replaced with cement and fine aggregate, respectively.
\end{abstract}

Keywords: Copper slag, silica fume, by-product.

\section{INTRODUCTION}

The major construction material being used worldwide is concrete which is a properly proportioned mixture of cement, water, fine and coarse aggregate and often, chemical and mineral admixture. In the $21^{\text {st }}$ century there is a great demand of aggregates mainly for the construction of buildings, road, etc for which the demand of natural resources is at the peak and hence in the coming scenario the shortage of these natural resources will be the crucial issue. Therefore, for overcoming of this massive problem, the artificial manufactured aggregates viz., copper slag and silica fume generated from the industrial wastes can be utilized as an alternative.

Copper slag is a waste material which is a partial or full substitution of either cement or aggregate. It is an industrial by-product formed during the process of smelting and refining of copper. Copper slag is having a promising future in the construction industry. Approximately 2.2-3.0 tons of copper slag is generated during each ton of copper production. In India, SIL, Tuticorin, Tamil Nadu is producing copper slag in highest percentage. Utilization of the by- products (copper slag) material in the substitution process also have a main advantage of eliminating the cost of dumping and minimizing the air as well as land pollution.

Another supplementary cementitious material (SCMs) is silica fume which is a by-product of smelting process in silicon and ferrosilicon industry. It is also known as microsilica, condensed silica fume, volatized silica or silica dust. Silica fumes helps in improving the durability as well mechanical properties of concrete due to formation of calcium silicate hydrate (C-S-H). Silica fume is also called as a pozzolanic material. Due to its high firmness and high silica content it is basically used in concrete to improve its properties. It has an another important property of having a very fine vitreous particle of about 13000 to $30000 \mathrm{~m}^{2} / \mathrm{kg}$ of surface area which are 100 times smaller than the average cement particles. Therefore, use of aggregates obtained from the industrial wastes is the alternative source of the natural and artificial aggregates. Hence, an experimental program was designed to study the mechanical properties of concrete with partial replacement of cement with silica fume and fine aggregates with copper slag.

\section{EXPERIMENTAL PROGRAMME}

The Experimental Program was designed to investigate the effect on the mechanical properties of the concrete by using copper slag as a partial replacement for fine aggregate with different proportions viz., $10 \%, 20 \%, 30 \%, 40 \%$ and $50 \%$ and with the fixed amount of silica fume i.e. (10\%) as a partial replacement for cement. For each test, average of two samples from each mix was tested at each curing age, and the average values were used for analysis.

\subsection{Materials Descriptions}

The various materials used in this research analysis were:

\subsubsection{Cement}

Ordinary Portland cement of 43 grades was used in this experimental study which was locally available in Moradabad. This cement is generally used in the construction industries having specific gravity 3.5 .

\subsubsection{Natural Coarse Aggregate (NCA)}

Locally available crushed stone aggregates having size of 20 $\mathrm{mm}$ to $10 \mathrm{~mm}$ used in this analysis was locally available in Moradabad. 


\subsubsection{Natural Fine Aggregate (NFA)}

This material was obtained from Ram Ganga River nearly situated in Moradabad.

\subsubsection{Silica Fume (SF)}

It is an important material used in this proposed research work which was obtained from Vadodra, Gujarat. Silica fumes are either used as a densified or undensified powder or as slurry at a concrete mixer. The physical property of silica fume consist of specific gravity (2.2), mean grain size $(0.1 \mu \mathrm{m})$ and specific area $\left(20,0000 \mathrm{~cm}^{2} / \mathrm{g}\right)$. The color of silica fume varies from light to dark grey in color. Chemical composition of silica fumes consist of various composition of chemicals viz., silicon dioxide $\left(\mathrm{SiO}_{2}, 96 \%\right)$, aluminum oxide $\left(\mathrm{Al}_{2} \mathrm{O}_{3}, 0.1 \%\right)$, iron oxide $\left(\mathrm{Fe}_{2} \mathrm{O}_{3}, 0.6 \%\right)$, calcium oxide $(\mathrm{CaO}, 0.1 \%)$ and magnesium oxide $(\mathrm{MgO}, 0.2 \%)$.

\subsubsection{Copper Slag}

It is by-product manufactured during the smelting and refining process of copper. It has various physical and chemical properties such as specific gravity of copper slag is 2.73, firmness modulus is about 8.01 , crushing value is $26.37 \%$, impact value is $30.75 \%$ and water absorption is $30.75 \%$. The color of copper slag is like a black glassy particle with granular material in nature having a similar particle size range like sand.

Under chemical properties the chemical composition of different chemicals are as follows: $\mathrm{SiO}_{2}$ with $(25.85 \%)$, $\mathrm{Fe}_{2} \mathrm{O}_{3}(68.29), \mathrm{Al}_{2} \mathrm{O}_{3}(0.22 \%), \mathrm{CaO}(0.15 \%), \mathrm{Na}_{2} \mathrm{O}(0.58 \%)$, $\mathrm{K}_{2} \mathrm{O}(0.23 \%)$ and $\mathrm{TiO}_{2}(0.41 \%)$.

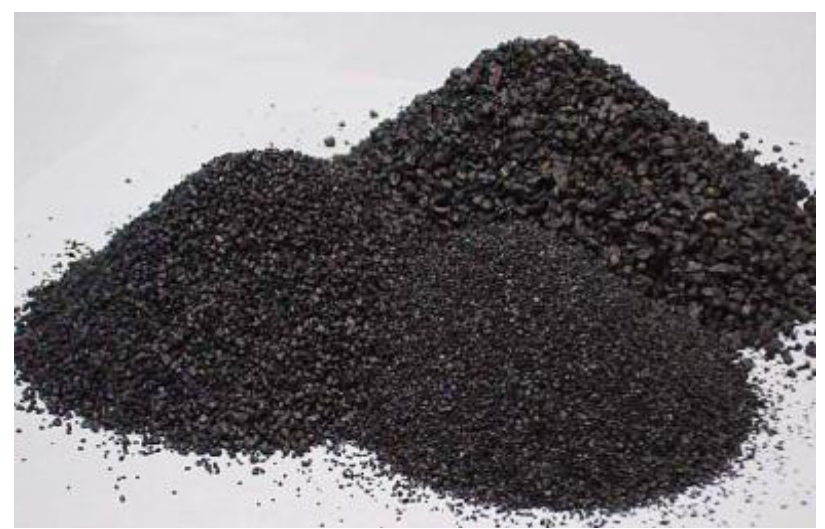

Fig. 2.1.5 Copper Slag (www.google.com)

\subsection{Mix Proportion}

Production of quality concrete requires meticulous care exercised at every stage of preparation of concrete.

Tentative Mixes of the Materials were used in the Proposed Study which is discussed below in the table:

\begin{tabular}{|l|l|}
\hline $\begin{array}{l}\text { Mix } \\
\text { Id }\end{array}$ & Description \\
\hline M0 & $90 \% \mathrm{PC}+10 \% \mathrm{SF}+100 \% \mathrm{NFA}+100 \% \mathrm{NCA}$ \\
\hline
\end{tabular}

\begin{tabular}{|l|l|}
\hline M1 & $90 \% \mathrm{PC}+10 \% \mathrm{SF}+90 \% \mathrm{NFA}+10 \% \mathrm{SFA}+100 \% \mathrm{NCA}$ \\
\hline M2 & $90 \% \mathrm{PC}+10 \% \mathrm{SF}+80 \% \mathrm{NFA}+20 \% \mathrm{SFA}+100 \% \mathrm{NCA}$ \\
\hline M3 & $90 \% \mathrm{PC}+10 \% \mathrm{SF}+70 \% \mathrm{NFA}+30 \% \mathrm{SFA}+100 \% \mathrm{NCA}$ \\
\hline M4 & $90 \% \mathrm{PC}+10 \% \mathrm{SF}+60 \% \mathrm{NFA}+40 \% \mathrm{SFA}+100 \% \mathrm{NCA}$ \\
\hline M5 & $90 \% \mathrm{PC}+10 \% \mathrm{SF}+50 \% \mathrm{NFA}+50 \% \mathrm{SFA}+100 \% \mathrm{NCA}$ \\
\hline
\end{tabular}

Where, *PC-Portland Cement

*SF-Silica Fume

*NFA-Natural Fine Aggregate

*NCA-Natural Coarse aggregate

*SFA-Secondary Fine Aggregate (i.e. Copper Slag)

\subsection{Batching and Mixing}

For each mix, the specified quantities of the constituents were batched by weight. Concrete was mixed using mixer machine within the laboratory. Before starting the mixer machine, the mixer drum was washed and allowed to dry for couple of minutes. After this, mixing was done by placing copper slag initially and than other materials was mixed.

\subsection{Casting and Curing}

All the specimens were cast using steel moulds and the joints between the sections of the mould were thinly coated with crude oil. They were de-moulded after 24 hours and cured in water at the room temperature of $25^{\circ} \mathrm{C}$.

\section{RESULTS AND DISCUSSION}

Result on properties of hardened concrete:

\subsection{Compressive Strength}

Concrete cubes of size 150 × 150 × $150 \mathrm{~mm}$ were casted for all the concrete mixes. All the cubes were tested in saturated condition after wiping out the surface moisture. Two cubes from each mix were tested and there average values were used in the analysis using compression testing machine (CTM). The compressive strength of test cubes was determined at the ages of 7, 14 and 28 days. Data for compressive strength are interpreted in Table 3.1.

Table- 3.1: Average Compressive Strength (Mpa) depicted

\begin{tabular}{|l|l|l|l|}
\hline MIX & \multicolumn{3}{l|}{ at days, 14 days and 28 days interval } \\
& $\begin{array}{l}\text { Compressive Strength } \\
\text { (Mpa) }\end{array}$ & \multicolumn{2}{l|}{} \\
\cline { 2 - 4 } & 7 days & 14 days & 28 days \\
\hline M0 & 19.82 & 26.46 & 32.55 \\
\hline M1 & 23.99 & 28.80 & 36.22 \\
\hline M2 & 25.09 & 32.50 & 38.58 \\
\hline M3 & 27.56 & 37.86 & 41.50 \\
\hline M4 & 31.40 & 38.22 & 46.86 \\
\hline M5 & 30.20 & 36.39 & 44.24 \\
\hline
\end{tabular}




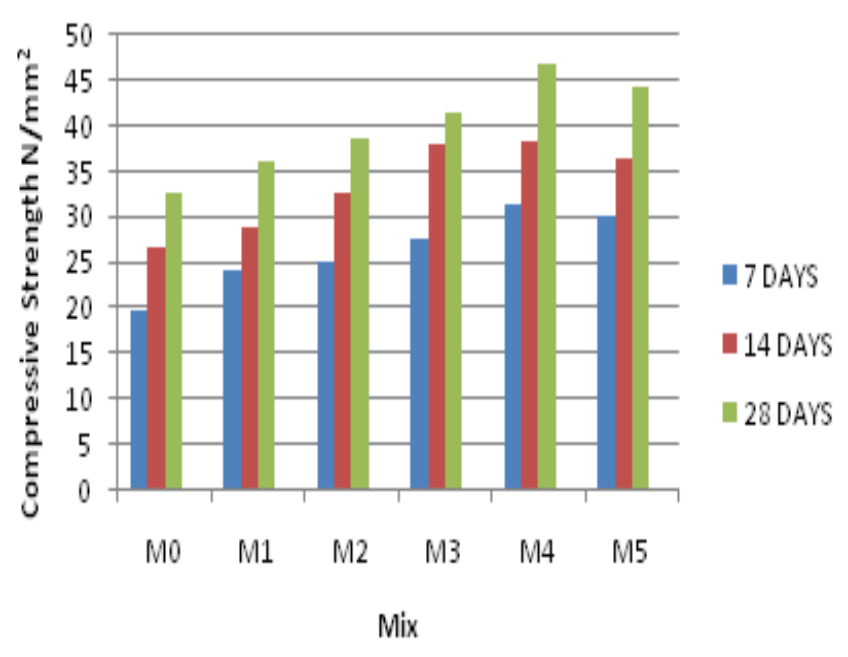

Fig-3.1: Compressive Strengths test result for different mixes

From the test results, it can be seen that the compressive strength of the new concrete mixes with $10 \%, 20 \%, 30 \%$, $40 \%$ and $50 \%$ fine aggregate replacement with Copper Slag and were higher than the control mix at all ages. It is evident from the above table that compressive strength of all mixes continued to increase with the increase in age. From the above table the highest compressive strength was achieved by $40 \%$ replacement of copper slag, which was found about 31.40 Mpa compared with $19.82 \mathrm{Mpa}$ for the control mixture at 7 days. This means that there is an increase in the strength of almost $58 \%$ compared to the control mix at 7 days. From the above table the highest compressive strength was achieved by $40 \%$ replacement of copper slag, which was found about 38.22 Mpa compared with26.46 Mpa for the control mixture at 14 days. This means that there is an increase in the strength of almost $44 \%$ compared to the control mix at14 days. From the above table the highest compressive strength was achieved by $40 \%$ replacement of copper slag, which was found about 46.86 Mpa compared with $32.55 \mathrm{Mpa}$ for the control mixture at 28 days. This means that there is an increase in the strength of almost $43 \%$ compared to the control mix at 28 days.

\subsection{Tensile Strength}

The result of tensile strength is presented in table 3.2. All the specimens were tested in saturated condition after wiping out the surface moisture. Average value of two specimens from each mix was taken which were tested at the age of 7,14 and 28 days.

Table- 3.2: Average Tensile Strength (Mpa) depicted at 7 days, 14 days and 28 days interval

\begin{tabular}{|l|l|l|l|}
\hline MIX & \multicolumn{3}{|l|}{$\begin{array}{l}\text { Tensile Strength } \\
\text { (Mpa) }\end{array}$} \\
\cline { 2 - 4 } & 7 days & 14 days & 28 days \\
\hline M0 & 4.51 & 5.45 & 7.24 \\
\hline M1 & 4.90 & 5.67 & 8.28 \\
\hline M2 & 5.10 & 5.98 & 8.80 \\
\hline M3 & 5.34 & 6.51 & 9.00 \\
\hline
\end{tabular}

\begin{tabular}{|l|l|l|l|}
\hline M4 & 5.90 & 7.25 & 9.50 \\
\hline M5 & 5.10 & 7.10 & 9.10 \\
\hline
\end{tabular}

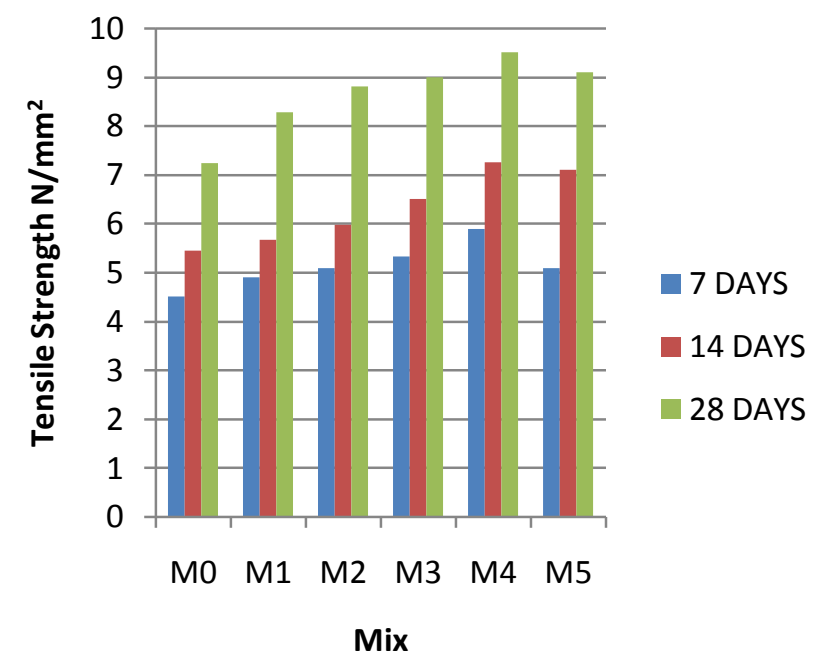

Fig-3.2: Tensile Strengths test result for different mixes

From the figure it is observed that with the increase in the percentage of copper slag the 7 days highest tensile strength was achieved by $40 \%$ replacement of copper slag, which was found about 5.90Mpa compared with4.51 Mpa for the control mixture at 7 days. This means that there is an increase in the strength of almost $30 \%$ compared to the control mix at 7 days, the 14 days highest tensile strength was achieved by $40 \%$ replacement of copper slag, which was found about 7.25Mpa compared with5.45 Mpa for the control mixture. This means that there is an increase in the strength of almost $33 \%$ compared to the control mix at 14days, the 28 days highest tensile strength was achieved by $40 \%$ replacement of copper slag, which was found about 9.50Mpa compared with7.24 Mpa for the control mixture at 28days. This means that there is an increase in the strength of almost $31 \%$ compared to the control mix at 28 days.

\subsection{Flexural Strength}

Beam specimens of size $500 \mathrm{~mm}$ X $100 \mathrm{~mm}$ X $100 \mathrm{~mm}$ were used casted and tested to determine the modulus of rupture at the age of 28 days. The bearing surfaces of the supporting and loading rollers are wiped and clean and any loose sand or other material removed from the surfaces of the specimen where they are to make contact with the rollers. The specimen is then placed in the machine in such a manner that the load is applied to the uppermost surface as cast in the mould, along two lines spaced $13.3 \mathrm{~cm}$ apart. The axis of the specimen is carefully aligned with the axis of loading device.

Table - 3.3: Flexural Strength (Mpa) depicted at 28 days

\begin{tabular}{|l|l|}
\hline MIX & $\begin{array}{l}\text { Flexural Strength (Mpa) } \\
f c r(28 \text { days })\end{array}$ \\
\hline M0 & 3.72 \\
\hline M1 & 3.95 \\
\hline M2 & 4.12 \\
\hline
\end{tabular}




\begin{tabular}{|l|l|}
\hline M3 & 4.40 \\
\hline M4 & 4.65 \\
\hline M5 & 4.24 \\
\hline
\end{tabular}

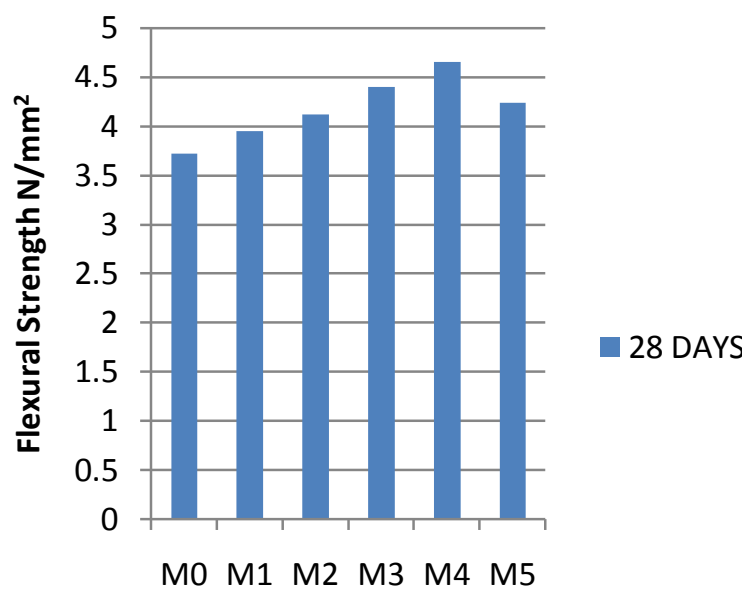

Mix

Fig-3.3: Flexural Strengths test result for different mixes

The 28 days highest flexural strength was achieved by $40 \%$ replacement of copper slag, which was found about 4.65Mpa compared with3.72 Mpa for the control mixture. This means that there is an increase in the strength of almost $25 \%$ compared to the control mix at 28 days.

\section{CONCLUSION}

From the above results, following remarks can be concluded:

1. The compressive strength of the new concrete increased with the increase in copper slag content up to a replacement level of $40 \%$, maximum compressive strength of concrete increased by $58 \%$ at $40 \%$ replacement of fine aggregate by copper slag.

2. The tensile strength of the new concrete has increased up to a replacement percentage of $40 \%$, maximum tensile strength of the new concrete increased by $33 \%$ at $40 \%$ replacement of fine aggregate by copper slag.

3. Maximum flexural strength of the new concrete increased by $25 \%$ at $40 \%$ replacement of fine aggregate by copper slag.

4. Beyond the replacement level of $40 \%$ of fine aggregate with copper slag in concrete, a decrease in strength was observed.

\section{REFERENCES}

[1]. Arivalagan.S (2013):"Experimental Study on the Flexural Behaviour of Reinforced Concrete Beams as Replacement of Copper Slag as Fine Aggregate" Journal of Civil Engineering and Urbanism Volume 3, Issue 4(176182).

[2]. R R Chavan\& D B Kulkarni (2013): "Performance of Copper Slag on Strength properties as Partial Replace of Fine Aggregate in Concrete Mix Design" International Journal of Advanced Engineering Research and Studies.
[3]. Dr.T.Ch.Madhavi (2014):“Copper Slag in Concrete as Replacement Material" "International Journal of Civil Engineering and Technology", Volume 5, Issue 3(327-332) [4]. I.J. Karthick (2014): "Experimental Study on Strength Characteristics on M2O Concrete with Partial Replacement of Cement with Fly Ash and Replacement of Fine Aggregate with Copper Slag” Vol. 1, Issue 1(26-29).

[5]. N. K. Amudhavalli (2012): Effects of Silica Fume on Strength and Durability Parameters of Concrete", International Journal of Engineering Sciences \& Emerging Technologies, Volume 3, Issue 1 (28-35).

[6]. Debabrata Pradhan \& D. Dutta (2013) : "Influence of Silica Fume on Normal Concrete" Int. Journal of Engineering Research and Applications, Vol. 3, Issue 5, pno.79-82

[7]. Prof. Vishal S. Ghutke (2014): "Influence of silica fume on concrete", Journal of Mechanical and Civil Engineering (IOSR-JMCE), (44-47) 